\title{
Research on Comprehensive Quantitative Evaluation Method of the Operation Mode of Urban Distribution Network
}

\author{
Mei Huang \\ Co. Ltd. \\ Shenzhen, China \\ szmay@139.com \\ Yong Zhao \\ Dongfang Electronics Corporation \\ Yantai, China \\ zhaoyong@dongfang-china.com
}

Shenzhen Power Supply Bureau of Guangdong Power Grid

\author{
Mingyu Zhou \\ School of Electronic Information and Electrical Engineering \\ Shanghai Jiaotong University \\ Shanghai, China \\ starcraft1996@126.com \\ Hengyuan Bai \\ Shenzhen Power Supply Bureau of Guangdong Power Grid \\ Co. Ltd. \\ Shenzhen, China \\ bhybs1655@163.com
}

\author{
Yong Liu \\ Shanghai Proinvent Information Technology Ltd. \\ Shanghai, China \\ yongliu888@163.com
}

\begin{abstract}
In order to make a quantitative comprehensive evaluation of the operation mode of the urban distribution network, this paper proposes a method which uses the economy of Lagrangian function to determine the weights of the evaluation indexes. This method uses Lagrangian function to establish the comprehensive quantitative evaluation model which uses the security, economy and reliability indexes as the constraints, uses different objective functions according to different demand, and is based on a united dimension. This method uses the principle that the Lagrange multipliers of the nonlinear programming represent the influence degree of the corresponding constraints on the objective function, and then uses the Lagrangian function as the result of the evaluation. The result of a numerical example proves that this method can make evaluation of the operation mode of the distribution network, which proves the effectiveness and rationality of the method.
\end{abstract}

Keywords-Distribution Network; Operation Mode; Lagrangian Function; Comprehensive Quantitative Evaluation

\section{INTRODUCTION}

The operation mode of city distribution network is the power supply mode which is obtained by grid operation staff by reference to the historical data of distribution network operation, the present situation of the distribution network and the results of load forecasting. Traditional assessment methods of distribution network operation mode often rely on the subjective judgment of grid operation staff, and these methods lack scientificity and rationality. Therefore it is necessary to find a method for comprehensive quantitative evaluation of the distribution network operation mode.

Up to now, many evaluation index systems have been established in order to make evaluation of the distribution network from different aspects. References [1-2] summarize the comprehensive evaluation index system of the distribution network. However, the comprehensive evaluation methods of the distribution network operation mode have many disadvantages. The main comprehensive evaluation methods are entropy weight method, data envelopment analysis (DEA) method, analytic hierarchy process (AHP) method, fuzzy evaluation method and principal component analysis method. The entropy weight method [3] is objective, but the practical implications of the data have been ignored. The DEA method [4] is available for both small-scale and large-scale networks, but the actual situation of the indexes has been concealed. The AHP method [5] combines quantitative analysis and qualitative analysis, but it is subjective. The fuzzy evaluation method [6] is highly available and scalable, but the evaluation result will be inaccurate if some of the indexes have the same components. The principal component analysis method [7] uses fewer variables instead of the original large number of variables, but the weights of the original indexes can't be figured out so we are unable to find out the significance of the original indexes. 
This paper presents a method for comprehensive quantitative evaluation by using the economy of Lagrangian function, in consideration of the disadvantages of traditional methods. This method achieves the purpose of comprehensive quantitative evaluation by using the Lagrangian function of optimization mathematical model, in consideration of the reliability, security and economy of distribution network. This method not only takes the actual meaning of data into account and is independent of the assessment environment, but also overcomes the problem of subjective weight determination. Besides, it is extensible under the environment of multidimensional data. Considering that it is difficult to solve the optimization problem of complicated distribution network, this paper presents a simplified calculation method by transforming the nonlinear programming problem into linear programming problem. The case given in this paper shows that this method is effective and efficient.

\section{MATHEMATICAL MODEL}

The optimal distribution network operating status can be described as the following mathematical model:

$$
\begin{array}{r}
\min \quad f(x) \\
\text { s.t. }\left\{\begin{array}{l}
h(x)=0 \\
g(x) \leq 0
\end{array}\right.
\end{array}
$$

Where,

$x$ : the state variable vector, which can also be expressed as $\left(x_{1}, x_{2}, \ldots, x_{n}\right)^{\mathrm{T}}$, where $n$ is the number of the variables in the state variable.

$f(x)$ : the objective function.

$h(x)$ : the equality constraint vector, which can also be expressed as $\left(h_{1}(x), h_{2}(x) \ldots, h_{k}(x)\right)^{\mathrm{T}}$, where $k$ is the number of the equality constraints.

$g(x)$ : the inequality constraint vector, which can also be expressed as $\left(g_{1}(x), g_{2}(x) \ldots, g_{m}(x)\right)^{\mathrm{T}}$, where $m$ is the number of the inequality constraints.

In the above nonlinear programming, the objective function often represents the economy of the distribution network, such as the network loss. Similarly, the equality constraints are often represented as the power flow formulas, and the equality constraints often represent the security and reliability of the distribution network.

The feasible region of the nonlinear programming (1) consists of the above-mentioned equality and inequality constraints, and a normal operation mode is a certain feasible point in the feasible region. Since the equality constraints are usually met in actual operation modes, the feasible region can be considered to consist of the inequality constraints. In other words, the inequality constraints structure the bound of the operation modes of the distribution network. Besides, the optimal solution of the nonlinear programming (1) is the optimal operation mode of the distribution network. Otherwise, an arbitrary operation mode in the feasible region is only a feasible mode.

Since different kinds of evaluation indexes have different kinds of dimension, we must find methods to transform different kinds of dimension into the same one instead of simply adding together the values of the indexes. The nonlinear programming (1) can be equivalent to the following Lagrangian function:

$$
L(x, \alpha, \beta)=f(x)+\sum_{i=1}^{k} \alpha_{i} h_{i}(x)+\sum_{i=1}^{m} \beta_{i} g_{i}(x)
$$

Where,

$$
\begin{aligned}
& \alpha \text { : the Lagrange multipliers of the equality constraints. } \\
& \beta \text { : the Lagrange multipliers of the inequality constraints. } \\
& k \text { : the number of the equality constraints. } \\
& m \text { : the number of the inequality constraints. }
\end{aligned}
$$

The Lagrangian function is very important in economics. The main task of economics is to achieve optimal allocation of resources. In other words, the main task of economics is to achieve the least cost or the most profit with the constraints of the resources. In fact, the economic significance of the Lagrangian function is the optimal allotment of the resources, and the Lagrange multipliers have different meanings with the change of the objective function and the constraints. For example, when the objective function is the most profit and the constraints are the budget, the Lagrange multipliers represent the marginal utility of the budget. For another example, when the objective function is the least cost and the constraints are the output, the Lagrange multipliers represent the marginal utility of the output. Similarly, the Lagrange multipliers in the nonlinear programming (1) represent the influence degree of the corresponding constraints on the objective function. In other words, the Lagrange multipliers can transform different kinds of evaluation indexes into the economy index, which means that the aim of transforming different kinds of dimension into the same one is realized. This paper realizes the comprehensive evaluation of the distribution network based on the above characteristics of the Lagrangian function.

\section{EVAluAtion IndeXES AND MEthodOLOGY}

\section{A. Evaluation Indexes}

1) customer average interruption frequency

$$
\frac{\sum_{i} \lambda_{i} N_{i}}{\sum_{j \in E F F} N_{j}} \geq 0
$$

Where,

$\lambda_{i}$ : the failure rate of load point $i$.

$N_{i}$ : number of customers of load point $i$.

$E F F$ : the set of the load points that are affected by the power failure. 
2) customer average interruption duration

$$
\frac{\sum_{i} U_{i} N_{i}}{\sum_{i} \lambda_{i} N_{i}} \geq 0
$$

Where,

$U_{i}$ : the average interruption duration of load point $i$.

3) average power availability index

$$
0 \leq \frac{8760 \sum_{i} N_{i}-\sum_{i} U_{i} N_{i}}{8760 \sum_{i} N_{i}} \leq 1
$$

4) voltage drop percentage

$$
0 \leq\left|\frac{V_{f}-V_{t}}{V_{f}}\right| \leq 1
$$

Where,

$V_{f}$ : the voltage of the starting node of a branch.

$V_{t}$ : the voltage of the end node of a branch.

5) node voltage deviation

$$
V_{i \min } \leq V_{i} \leq V_{i \max }
$$

Where,

$V_{i}$ : the voltage of node $i$.

$V_{i \text { min }}$ : the lower limit value of the voltage of node $i$.

$V_{i \max }$ : the upper limit value of the voltage of node $i$.

6) voltage qualification rate

$$
0 \leq \frac{N_{p}}{N_{t}} \leq 1
$$

Where,

$N_{p}$ : number of nodes whose voltage is qualified.

$N_{t}$ : number of total nodes.

7) three-phase voltage imbalance rate

$$
0 \leq \frac{\mathrm{I}_{\max }^{(3)}-\mathrm{I}_{\min }^{(3)}}{\mathrm{I}_{\max }^{(3)}} \leq 1
$$

Where,

$\mathrm{I}_{\max }^{(3)}$ : the maximum value of the three-phase current.

$\mathrm{I}_{\min }^{(3)}$ : the minimum value of the three-phase current.

8) reactive power configuration

$$
0 \leq Q_{R i} \leq Q_{R i \max }
$$

Where,

$Q_{R i}$ : the reactive power compensation value of node $i$.
$Q_{R i \max }:$ the upper limit value of reactive power compensation of node $i$.

\section{B. Methodology}

According to (2), we can obtain the following formula for a certain feasible point $x_{0}$ :

$$
L\left(x_{0}, \alpha, \beta\right)=f\left(x_{0}\right)+\sum_{i=1}^{k} \alpha_{i} h_{i}\left(x_{0}\right)+\sum_{i=1}^{m} \beta_{i} g_{i}\left(x_{0}\right)
$$

Since every feasible point satisfies the power flow formulas, we can obtain the following formula:

$$
L\left(x_{0}, \alpha, \beta\right)=f\left(x_{0}\right)+\sum_{i=1}^{m} \beta_{i} g_{i}\left(x_{0}\right)
$$

According to the analysis of the economic significance of the Lagrangian function in section II, we can obtain that the Lagrangian function can merge the economy indexes, the security indexes and the reliability indexes into a single formula. So we use the result of (12) as the quantitative result of the comprehensive evaluation. The quantitative comprehensive evaluation method of the operation mode of the distribution network using the economy of the Lagrangian function is described in the following procedures.

1) Establish the evaluation index system of the distribution network which is to be evaluated.

2) Obtain the nonlinear programming (1) using the data and the indexes of the distribution network. The objective function is the loss of the distribution network. The equality constraints are the power flow formulas. The inequality constraints are the formulas of the indexes.

3) Calculate $\beta$, which is the Lagrange multipliers of the inequality constraints, using interior point method.

4) Calculate L using (12), and regard it as the quantitative evaluation result of the operation mode of the distribution network.

According to the analysis of the economic significance of the Lagrangian function in section II, we can learn that the operation mode of the distribution network will be better if the value of $L$ is smaller.

\section{CASE Study}

The calculation structure was achieved using MATLAB 8.3 under WINDOWS 8.1 environment, and a 12-node distribution network was tested to verify the feasibility of this method. Fig. 1 shows the 12-node distribution network. The distribution network has a feeder (node 1), 11 load nodes, 15 branches. The numbers on the lines are the numbers of the branches. 


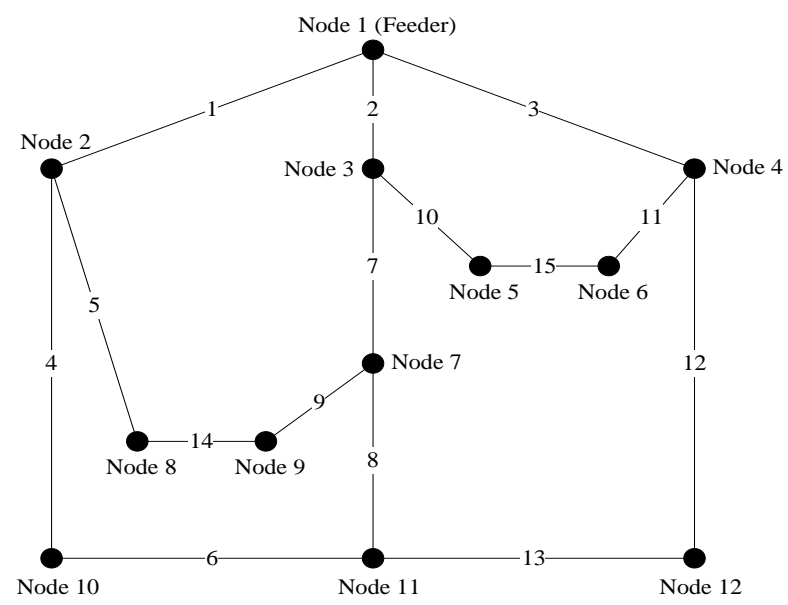

Fig. 1. Wiring diagram of a 12-node distribution network

The original data are included in TABLE I and TABLE II. The per-unit system is used, so all the units of the data are omitted. The base capacity of the network is 100MVA, and the base voltage is $23 \mathrm{kV}$. The voltage of the feeder (Node 1 ) is 1.0 p.u., and all the lower limit values of reactive power compensation are 0 . The total load capacity is 2510+j1510MVA.

TABLE I. PARAMETERS OF THE NODES OF THE DISTRIBUTION NETWORK

\begin{tabular}{|c|c|c|c|}
\hline $\begin{array}{c}\text { Node } \\
\text { number }\end{array}$ & $\begin{array}{c}\text { Active } \\
\text { power load }\end{array}$ & $\begin{array}{c}\text { Reactive } \\
\text { power load }\end{array}$ & $\begin{array}{c}\text { Upper limit value of reactive } \\
\text { power compensation }\end{array}$ \\
\hline 1 & - & - & - \\
\hline 2 & 2.0 & 1.6 & - \\
\hline 3 & 4.0 & 2.7 & - \\
\hline 4 & 1.0 & 0.9 & 1.8 \\
\hline 5 & 1.0 & 0.9 & - \\
\hline 6 & 1.0 & 0.7 & 1.2 \\
\hline 7 & 5.0 & 3.0 & 0.2 \\
\hline 8 & 3.0 & 1.5 & 0.6 \\
\hline 9 & 0.6 & 0.1 & 0.25 \\
\hline 10 & 2.0 & 0.8 & 3.7 \\
\hline 11 & 4.5 & 2.0 & - \\
\hline 12 & 1.0 & 0.9 & - \\
\hline
\end{tabular}

TABLE III. RESUlTS UNDER DIFFERENT REACTIVE POWER COMPENSATION CONDITIONS

\begin{tabular}{|c|c|c|c|c|c|c|c|c|}
\hline $\begin{array}{l}\text { Operation } \\
\text { mode } \\
\text { number }\end{array}$ & $\begin{array}{c}\text { Reactive power } \\
\text { compensation } \\
\text { value of Node } 5\end{array}$ & $\begin{array}{c}\text { Reactive power } \\
\text { compensation } \\
\text { value of Node } 7\end{array}$ & $\begin{array}{c}\text { Reactive power } \\
\text { compensation } \\
\text { value of Node } 8\end{array}$ & $\begin{array}{c}\text { Reactive power } \\
\text { compensation } \\
\text { value of Node } 9\end{array}$ & $\begin{array}{c}\text { Reactive power } \\
\text { compensation } \\
\text { value of Node } \\
10 \\
\end{array}$ & $\begin{array}{c}\text { Reactive power } \\
\text { compensation } \\
\text { value of Node } \\
11 \\
\end{array}$ & $\begin{array}{c}\text { Total } \\
\text { active } \\
\text { power } \\
\text { loss } \\
\end{array}$ & $\begin{array}{c}\text { Evaluation } \\
\text { result }\end{array}$ \\
\hline 1 & 0 & 0 & 0 & 0 & 0 & 0 & 0.5239 & 0.4734 \\
\hline 2 & 1.8 & 0 & 0 & 0 & 0 & 0 & 0.5113 & 0.4659 \\
\hline 3 & 0 & 1.2 & 0 & 0 & 0 & 0 & 0.4951 & 0.4664 \\
\hline 4 & 0 & 0 & 0.2 & 0 & 0 & 0 & 0.5177 & 0.4714 \\
\hline 5 & 0 & 0 & 0 & 0.6 & 0 & 0 & 0.5067 & 0.4684 \\
\hline 6 & 0 & 0 & 0 & 0 & 0.25 & 0 & 0.5208 & 0.4706 \\
\hline 7 & 0 & 0 & 0 & 0 & 0 & 3.7 & 0.5000 & 0.4506 \\
\hline 8 & 0.9 & 0.6 & 0.1 & 0.3 & 0.125 & 1.85 & 0.4694 & 0.4413 \\
\hline 9 & 1.8 & 1.2 & 0.2 & 0.6 & 0.25 & 3.7 & 0.4402 & 0.4344 \\
\hline 10 & 1.73 & 1.19 & 0.19 & 0.59 & 0.17 & 3.14 & 0.4404 & 0.4336 \\
\hline
\end{tabular}

We can learn from TABLE III that although the active power loss of operation mode 9 is less than that of operation mode 10 , the evaluation result of operation 10 is smaller than that of operation mode 9 . This is because there are some problems with the safety and reliability of the network under
TABLE II. PARAMETERS OF THE BRANCHES OF THE DISTRIBUTION NETWORK

\begin{tabular}{|c|c|c|c|c|}
\hline $\begin{array}{c}\text { Branch } \\
\text { number }\end{array}$ & $\begin{array}{c}\text { Starting } \\
\text { node }\end{array}$ & $\begin{array}{c}\text { End } \\
\text { node }\end{array}$ & $\begin{array}{c}\text { Branch } \\
\text { resistance }\end{array}$ & $\begin{array}{c}\text { Branch } \\
\text { reactance }\end{array}$ \\
\hline 1 & 1 & 2 & 0.075 & 0.1 \\
\hline 2 & 1 & 3 & 0.11 & 0.11 \\
\hline 3 & 1 & 4 & 0.11 & 0.11 \\
\hline 4 & 2 & 10 & 0.09 & 0.18 \\
\hline 5 & 2 & 8 & 0.08 & 0.11 \\
\hline 6 & 10 & 11 & 0.04 & 0.04 \\
\hline 7 & 3 & 7 & 0.08 & 0.11 \\
\hline 8 & 7 & 11 & 0.08 & 0.11 \\
\hline 9 & 7 & 9 & 0.11 & 0.11 \\
\hline 10 & 3 & 5 & 0.11 & 0.11 \\
\hline 11 & 4 & 6 & 0.09 & 0.12 \\
\hline 12 & 4 & 12 & 0.08 & 0.11 \\
\hline 13 & 11 & 12 & 0.04 & 0.04 \\
\hline 14 & 8 & 9 & 0.04 & 0.04 \\
\hline 15 & 5 & 6 & 0.04 & 0.04 \\
\hline
\end{tabular}

We use the active power loss as the objective function in the nonlinear programming (1), which is as follows:

$$
\min f(x)=P_{G}-\sum_{i} P_{D i}
$$

Where,

$P_{G}:$ the active power injection of Node 1 .

$P_{D i}$ : the active power load of Node $i$.

\section{A. Results and Analysis under Different Reactive Power Compensation Conditions}

In this distribution network, the switches of Branch 5, Branch 8, Branch 10 and Branch 13 are off under the normal operation mode. So there are 11 branches at work and 6 nodes with reactive power compensation equipments. The calculation results under different reactive power compensation conditions are shown in TABLE III. 
All the Lagrange multipliers of the inequality constraints are calculated using interior point method, and they are used as the weights of certain indexes. TABLE IV shows part of the weights under operation mode 10 .

TABLE IV. PART OF THE WeIghtS UNDER OPERATION MOdE 10

\begin{tabular}{|l|l|l|l|l|}
\hline $\begin{array}{c}\text { Node } \\
\text { number }\end{array}$ & $\begin{array}{c}\text { Weight of } \\
\text { the upper } \\
\text { limit } \\
\text { constraint } \\
\text { of the } \\
\text { voltage }\end{array}$ & $\begin{array}{c}\text { Weight of } \\
\text { the lower } \\
\text { limit } \\
\text { constraint } \\
\text { of the } \\
\text { voltage }\end{array}$ & $\begin{array}{c}\text { Weight of the } \\
\text { upper limit } \\
\text { constraint of } \\
\text { reactive power } \\
\text { compensation }\end{array}$ & $\begin{array}{c}\text { Weight of the } \\
\text { lower limit } \\
\text { constraint of } \\
\text { reactive power } \\
\text { compensation }\end{array}$ \\
\hline 2 & 0.0019 & 0.0022 & - & - \\
\hline 3 & 0.0017 & 0.0025 & - & - \\
\hline 4 & 0.0019 & 0.0021 & - & - \\
\hline 5 & 0.0019 & 0.0022 & 0.0030 & 0.0001 \\
\hline 6 & 0.0019 & 0.0022 & - & - \\
\hline 7 & 0.0015 & 0.0029 & 0.0183 & 0.0002 \\
\hline 8 & 0.0015 & 0.0032 & 0.0226 & 0.0010 \\
\hline 9 & 0.0015 & 0.0031 & 0.0206 & 0.0003 \\
\hline 10 & 0.0018 & 0.0023 & 0.0024 & 0.0012 \\
\hline 11 & 0.0018 & 0.0023 & 0.0004 & 0.0001 \\
\hline 12 & 0.0019 & 0.0022 & - & - \\
\hline
\end{tabular}

\section{B. Results and Analysis under Different Conditions with Different Branches off}

TABLE V shows the results under different conditions with different branches off. There are 11 branches at work and 6 nodes with reactive power compensation in each operation mode. In TABLE $\mathrm{V}$, no compensation means the reactive power compensation value of each node with reactive power compensation equipments is 0 . Similarly, half compensation means the reactive power compensation value of each node with reactive power compensation equipments is half of the upper limit value of reactive power compensation, and full compensation means the reactive power compensation value of each node with reactive power compensation equipments is the upper limit value of reactive power compensation.

TABLE V. RESUlTS UNDER DIFFERENT CONDITIONS WITH DIFFERENT BRANCHES OFF

\begin{tabular}{|c|c|c|c|c|c|c|c|}
\hline \multirow[b]{2}{*}{$\begin{array}{c}\text { Operation mode } \\
\text { number }\end{array}$} & \multirow[b]{2}{*}{$\begin{array}{l}\text { Numbers of the } \\
\text { branches off }\end{array}$} & \multicolumn{2}{|c|}{ No compensation } & \multicolumn{2}{|c|}{ Half compensation } & \multicolumn{2}{|c|}{ Full compensation } \\
\hline & & $\begin{array}{l}\text { Total active } \\
\text { power loss }\end{array}$ & $\begin{array}{c}\text { Evaluation } \\
\text { result }\end{array}$ & $\begin{array}{l}\text { Total active } \\
\text { power loss }\end{array}$ & $\begin{array}{c}\text { Evaluation } \\
\text { result }\end{array}$ & $\begin{array}{l}\text { Total active } \\
\text { power loss }\end{array}$ & $\begin{array}{c}\text { Evaluation } \\
\text { result }\end{array}$ \\
\hline 11 & $6,9,10,13$ & 0.5206 & 0.4822 & 0.4470 & 0.4278 & 0.4101 & 0.4101 \\
\hline 12 & $6,13,14,15$ & 0.5805 & 0.5506 & 0.4906 & 0.4728 & 0.4555 & 0.4498 \\
\hline 13 & $6,8,14,15$ & 0.4134 & 0.3744 & 0.3578 & 0.3354 & 0.3301 & 0.3244 \\
\hline 14 & $8,13,14,15$ & 0.4374 & 0.3991 & 0.3811 & 0.3591 & 0.3535 & 0.3478 \\
\hline 15 & $6,8,9,11$ & 0.4200 & 0.3726 & 0.3663 & 0.3397 & 0.3378 & 0.3321 \\
\hline 16 & $5,8,10,13$ & 0.5239 & 0.4734 & 0.4694 & 0.4413 & 0.4402 & 0.4344 \\
\hline
\end{tabular}

We can learn from TABLE $\mathrm{V}$ that although the active power loss of operation mode 14 under full compensation condition is less than that of operation mode 15 under half compensation condition, the evaluation result of operation 15 under half compensation condition is smaller than that of operation mode 14 under full compensation condition. This is because the disconnection of Branch 8, Branch 13, Branch 14, Branch 15 can make active power loss smaller, but this operation mode has the worse security and reliability, and the evaluation result is larger than operation mode 15 under half compensation condition. Besides, we can learn from TABLE V that operation mode 13 is the best operation mode.

\section{CONCLUSION}

This paper proposes a method to make comprehensive quantitative evaluation of the urban distribution network using the economy of Lagrangian function. This method overcomes the shortcoming of the existing evaluation methods that the determination of the weights of the indexes involves too much human intervention, and the calculation is simple. The result of a numerical example proves that this method can make evaluation of the operation mode of the distribution network, which proves the effectiveness and rationality of the method. Besides, when we have some new indexes to calculate, we just need to use them as the new constraints of the nonlinear programming. In a word, the proposed method can solve the problems that the current methods is lack of rationality, and this method is extensible and effective, which can provide solid foundation to future distribution network planning.

\section{REFERENCES}

[1] Silong Lu, Jianping Yu, Jun Wang, Xiaolan Shen, "Study and application of the evaluation index system for distribution network", Electricity Distribution (CICED), 2008 China International Conference on. IEEE, pp. 1-6, 2008

[2] Dongvang Lin, Da Lin, Huifang Wang, "Index system for condition evaluation of distribution network based on Big Data", Electricity Distribution (CICED), 2014 China International Conference on. IEEE, pp. 1005-1008, 2014

[3] Tianlei Zang, Zhengyou He, Qingquan Qian, “Distribution network service restoration multiple attribute group decision-making using entropy weight and group eigenvalue”. Intelligent System Design and Engineering Applications (ISDEA), 2013 Third International Conference on. IEEE, pp. 602-606, 2013.

[4] Yang Fu, Luije Liu, Rong Hu, Jialin Cao, "Modified interval DEA method for economic evaluation of distribution network". Innovative Computing, Information and Control, 2007. Second International Conference on. IEEE, pp. 598-598, 2007.

[5] Liming Duan, Nian Liu, Zongqi Liu, Jianhua Zhang, “A comprehensive evaluation method for distribution networks' disaster vulnerability based on group AHP”, Electricity Distribution (CICED), 2012 China International Conference on. IEEE, pp. 1-5, 2012.

[6] Wei Huang, Yanping Zhang, Jingyan Yang, Jianhua Zhang, "Evaluation of distribution networks based on the fuzzy method". Transmission and Distribution Conference and Exhibition, 2005/2006 IEEE PES. IEEE, pp 1116-1121, 2006

[7] Xinhua Gao, Zheng Yan, "Comprehensive assessment of smart grid construction based on principal component analysis and cluster analysis", Power System Technology, vol.37, No.8, pp.2238-2243, 2013. 